\title{
Biculturalism and Context: What Is Biculturalism, and When Is It Adaptive?
}

\section{Commentary on Mistry and Wu}

\author{
Seth J. Schwartz ${ }^{\mathrm{a}}$ Jennifer B. Unger ${ }^{\mathrm{b}}$ \\ a University of Miami, Miami, Fla., and ${ }^{b}$ Claremont Graduate University, Claremont, Calif., USA
}

\author{
Key Words \\ Acculturation $\cdot$ Biculturalism $\cdot$ Context $\cdot$ Culture
}

Mistry and $\mathrm{Wu}$ [this issue] introduce the concept of navigating across worlds, and this construct appears to represent a rough approximation of biculturalism. They also discuss conditions that may facilitate biculturalism and under which it might be more versus less adaptive. The most integral aspects of Mistry and Wu's argument, then, center around biculturalism, what it is, how it comes into being, and when it is most adaptive. The present commentary focuses on these three issues.

Biculturalism has been defined in a number of ways [e.g., Benet-Martínez \& Haritatos, 2005; Berry, 1997; Schwartz \& Zamboanga, 2008]. Most generally, biculturalism represents comfort and proficiency with both one's heritage culture and the culture of the country or region in which one has settled. It is applicable not only to immigrants who have come from other countries, but also to children of immigrants who - although they are born and raised in the receiving society - are likely deeply embedded in the heritage culture at home with their families [Portes \& Rumbaut, 2001, 2006]. It may also apply to individuals living in ethnic enclaves, where the heritage culture is likely to be maintained across generations, as well as to individuals from visible minority groups, who may be identified as different from the majority ethnic group even if their families have been in the receiving society for multiple generations [Huynh, Nguyen, \& Benet-Martínez, in press; Umaña-Taylor, in press]. The ethnic component of biculturalism is not only a reactive response to discrimination, as Mistry and Wu appear to suggest. It also represents a sense of pride in one's heritage, and a desire to hold on to that heritage [Umaña-Taylor, Yazedjian, \& Bámaca-Gómez, 2004].

But what exactly does biculturalism look like? How would we know it if we saw it? What are its functions? And when is it adaptive - and when is it not?

\section{KARGER}

Fax +4161306 1234

E-Mail karger@karger.ch www.karger.com (c) 2010 S. Karger AG, Basel

Accessible online at: www.karger.com/hde
Seth J. Schwartz, Department of Epidemiology and Public Health, Leonard M. Miller School of Medicine University of Miami, 1425 N.W. 10th Avenue Miami, FL 33136 (USA), Tel. +1 3052434359 Fax +1 305243 5577, E-Mail SSchwartz@med.miami.edu 


\section{What Is Biculturalism?}

The acculturation literature, from which the concept of biculturalism was originally derived [Berry, 1997; Szapocznik, Kurtines, \& Fernandez, 1980], has focused primarily on cultural behaviors such as language use, choice of friends, media preferences, and the like [Cabassa, 2003]. From this perspective, individuals are considered bicultural if they speak both the language of their heritage cultural context and the language of their receiving cultural context, have friends from both cultural backgrounds, and watch television programs and read magazines from both cultural contexts. Some writers [e.g., Benet-Martínez, Leu, Lee, \& Morris, 2002] have gone even further, suggesting that true biculturalism involves synthesizing the heritage and receiving cultures into a unique and personalized blend. From this perspective, the bicultural individual selects aspects from the heritage and receiving cultures and integrates them into an individualized 'culture' that is not directly reducible to either the heritage or receiving cultural streams. For example, a Chinese American person might eat hamburgers together with traditional Chinese vegetables, might speak 'Chinglish,' and might mix in social groups that include both Chinese and American friends.

We would argue here, however, that biculturalism involves more than just cultural behaviors. Along with our colleagues, we [Schwartz, Unger, Zamboanga, \& Szapocznik, submitted] have called for an expanded definition of acculturation that includes cultural practices, values, and identifications. Our view holds that a truly bicultural person would intermix their heritage and receiving cultural streams with regard to cultural practices, values, and identifications. This means that biculturalism implies not just behaving in ways consistent with the two cultural contexts, but also holding values from one's heritage and receiving cultural streams, as well as identifying with both cultures (e.g., as a Chinese American rather than just 'Chinese' or just 'American,' although either identification may be most salient in specific situations) [Benet-Martínez et al., 2002]. For example, our hypothetical Chinese American person might intermix traditional Asian values, such as deference to authority and respect for parents, with individualistic American values, such as confronting interpersonal disagreements directly and working hard to achieve personal success and recognition [Park \& Kim, 2008]. The person might also feel an allegiance both to the United States and to China, as well as to the local Chinese community. She might feel Chinese in comparison to her American peers and feel American in comparison to her Chinese peers, but she can function effectively in both cultural contexts.

\section{How Does Biculturalism Develop?}

Mistry and $\mathrm{Wu}$ address an important - and neglected - point when they note that biculturalism is facilitated by specific environmental conditions. When the individual is embedded in a community that integrates the heritage and receiving cultural streams, and where comfort with both cultures is essential for day-to-day living, then biculturalism is most likely to emerge. That is, in environments characterized by ethnogenesis [Flannery, Reise, \&Yu, 2001] - essentially, when the environment itself is bicultural - individuals who function within such environments should also 
be bicultural. Over time, this bicultural context itself may evolve and become dissimilar from both of the original cultures, although it incorporates elements from both cultures. However, this argument overlooks an important detail - even in a bicultural environment, not everyone can be characterized as bicultural. For example, Schwartz and Zamboanga [2008] surveyed a sample of Hispanic young adults in Miami and assessed cultural practices, values, and identifications, along with other culturally salient variables such as familial ethnic socialization, acculturative stress, and perceived discrimination. Although Miami is highly bicultural, and business and social transactions occur in both English and Spanish, sizeable numbers of individuals in the sample rated themselves as assimilated (mostly American, and not very Hispanic) or separated (mostly Hispanic, and not very American). Consistent with Mistry and $\mathrm{Wu}$, familial ethnic socialization - the extent to which parents teach their children about (and expose them to) the language, symbols, and traditions from the family's heritage culture [Umaña-Taylor, Bhanot, \& Shin, 2006] - most strongly differentiated bicultural individuals from those adopting other approaches to acculturation. The most fully bicultural individuals - those who integrated their Hispanic and American cultural streams - reported the highest levels of familial ethnic socialization. Individuals characterized as separated reported somewhat lower levels of familial ethnic socialization, and those characterized as assimilated reported among the lowest levels of familial ethnic socialization. Contrary to the fears of some political commentators [e.g., Huntington, 2004], then, parents who socialize their children strongly toward the family's heritage culture do not necessarily create a separated and 'un-American' outlook in their children.

What this suggests is somewhat more nuanced than what Mistry and Wu appear to imply. The family is not merely a conduit for larger environmental and cultural influences; rather, parents can actively decide how they want their children to acculturate, and their attempts to socialize their children culturally can complement - or clash with - the effects of the larger cultural context. This implies a degree of agency and intentional action on the part of parents, consistent with a developmental-contextual perspective. Although Mistry and Wu seem to describe the developmental-contextual perspective as somewhat deterministic, Lerner and colleagues' [e.g., Gestsdóttir \& Lerner, 2008; Lerner, Freund, DeStefanis, \& Habermas, 2001] perspective does indeed allow for such intentional action.

So, in essence, biculturalism can be said to emerge from one or both of two factors. The first is a social-cultural context characterized by ethnogenesis - where both the heritage and receiving cultural streams are emphasized and valued. The second involves active and intentional efforts by parents to socialize their children toward the heritage culture. Indeed, in more monocultural contexts oriented largely toward the receiving culture, parental socialization efforts may be especially important, given that the larger cultural context may not promote or encourage preservation of the heritage culture. Of course, many parents also actively encourage their children to integrate themselves into the receiving culture (e.g., achieving in school, making friends) [Portes \& Rumbaut, 2001], and adolescents often experiment with behaviors, values, and identities that go against those of their parents, especially if their peers engage in those behaviors - but in the end, parental ethnic socialization does tend to promote heritage culture retention in children [UmañaTaylor et al., 2006]. 


\section{When Is Biculturalism Most Adaptive?}

As Mistry and Wu note, biculturalism has often - but not always - emerged as the most adaptive approach to acculturation. Biculturalism, traditionally operationalized as endorsing the cultural practices characteristic of both the heritage and receiving cultural contexts, should help the person be comfortable in both settings [Chen, Benet-Martínez, \& Bond, 2008], use coping strategies from both cultures, and be able to interact with people from the larger society and from the heritage culture community. Some investigators have even found that bicultural individuals are more likely to display advanced reasoning (e.g., seeing both sides of an argument, understanding multiple perspectives on complex social issues) than individuals adopting other approaches to acculturation [Tadmor, Tetlock, \& Peng, 2009]. However, as Schwartz and Zamboanga [2008] have contended, biculturalism is most adaptive in a bicultural environment. Large gateway cities such as New York, Los Angeles, Toronto, London, Paris, Amsterdam, and Sydney receive large numbers of immigrants, and as a result, being able to navigate within multiple cultures provides a distinct advantage. On the other hand, in more monocultural areas, such as parts of the American Midwest and of Northern England, being bicultural may actually be a disadvantage - especially if the person has created a blended culture of her or his own that combines the heritage and receiving cultural streams. In some monocultural situations and contexts, it may be most adaptive to behave and think in ways that are more consistent with the receiving culture. According to Phinney and Devich-Navarro [1997], bicultural individuals may select various methods of integrating their two cultures, including behaving biculturally in all situations (blended biculturalism) or shifting their behaviors to be consistent with the cultural context of the situation (alternating biculturalism). The alternating bicultural strategy may be more adaptive in some monocultural contexts.

Take, for example, Mexican or Central American immigrants in rural, monocultural areas of the United States - especially the Deep South, the Midwest, and the Plains. Being bicultural implies integrating Hispanic and American cultural streams, such that the person incorporates some of the customs and values from the United States and some from the country of origin, as well as identifying both as American and as Mexican, Honduran, Salvadoran, and so on. Even if one is able to 'act American' at work or school, there may be other contexts - such as the family or the peer group - in which the person will display more heritage culture behaviors, values, and identifications. To the extent that these can be observed by receiving society members (e.g., hearing people speaking in Spanish, or seeing bumper stickers with foreign flags), these heritage culture displays may evoke defensive reactions from local residents. There is evidence that many Americans, especially White Americans who have had comparatively little contact with immigrants or foreigners, may view Spanish and other immigrant languages as a threat to American national unity and identity [Barker et al., 2001; Huntington, 2004]. Moreover, a public opinion poll taken in the early 2000s [Cornelius, 2002] found that Mexicans and Central Americans were among the most disliked immigrants in the United States - largely because of their large number, their willingness to work for low wages, and their use of a common immigrant language. So, in a monocultural American setting, Hispanic behaviors or identifications might be taken negatively by local residents and may elicit discrimination. An assimilated approach to acculturation - where the heritage culture 
is not displayed or identified with (at least not publicly, in the case of alternating biculturalism) - may be met with the least resistance from local community members. Of course, it may be possible to engage in American (or other receiving society) behaviors, without adopting American values or identifying as American, and it may be possible not to engage in heritage culture behaviors but still retain heritage values and identify with the heritage culture [Portes \& Rumbaut, 2001]. Moreover, immigrants may decide to display their ethnic pride despite threats of discrimination or persecution, and such displays may eventually help monocultural communities to adjust to the presence of immigrants.

The viability of biculturalism as an approach to acculturation may also vary across historical and generational time [e.g., Sterba, 2003] and be based on current events or political climate [Critelli, 2008]. In terms of variation across historical and generational time, earlier waves of immigrants to the United States were expected to assimilate and to 'leave their cultural baggage at the door,' whereas the current wave of immigrants has been more encouraged to retain their cultural heritage and to acquire American cultural practices, values, and identifications [Portes \& Rumbaut, 2001]. In terms of current events, the events of September 11, 2001 led to a more hostile context of reception for Muslim immigrants in the United States [Critelli, 2008] and in Europe [Bruss, 2008]. Moreover, the current American and European political climates have become somewhat hostile to immigrants in general. In the United States, this hostility has been directed largely toward immigrants from Mexico and Central America - with legislators (as well as the general public) focusing on strategies for identifying and deporting illegal immigrants. In 2004, the French Parliament passed a law banning Muslim headscarves in public schools [CBS News, 2004]. Such a hostile political climate may decrease the advantages of biculturalism and may increase the advantages of assimilating and blending in, especially for the specific immigrant groups who are the target of a hostile political climate.

One of the commonalities between the American and French examples introduced here is the sense of differentness between the mainstream culture and the immigrant groups against whom discrimination is directed. In the case of Mexicans and Central Americans in the United States, the divergence between the cultural beliefs, values, and practices of these countries (at least as perceived by most Americans) and those of the United States has led many Americans to view these immigrant groups as a threat to the American national identity - not only linguistically but also culturally, religiously, and economically [Huntington, 2004]. In the case of Muslims in France and other European countries, the perceived divide between Islamic and European values, beliefs, and behaviors has led to widespread fears about the inability or unwillingness of Muslims to integrate themselves religiously and culturally into European societies [Licata \& Klein, 2002; Licata, Sanchez-Mazas, \& Green, in press]. As Huntington noted, there is a fear among the majority ethnic group that these large immigrant groups will not attempt to fit into the larger society, but rather will create a separate cultural context that will threaten the unity of the country as a whole. This perceived threat, and the potential adverse reactions to it among receiving society individuals, may contribute to the decreasing adaptiveness of biculturalism in such ethnic groups in communities where their numbers are relatively small. 


\section{Conclusion}

In this commentary, we have laid out some ideas regarding what biculturalism is, how it develops, and when it may be more or less adaptive. Along with the article by Mistry and $\mathrm{Wu}$, this commentary is intended to spell out some of the complexity and nuance involving biculturalism (and cultural issues more generally). Biculturalism - as well as other approaches to acculturation - does not develop in isolation. Rather, it is likely a product of cultural and contextual forces that steer young people toward some cultural options and away from others. These forces are not constant, but rather change over time, vary across local and national contexts, and may operate differently depending on the immigrant group and receiving society in question. As suggested by a number of sources [e.g., Berry, 2006; Umaña-Taylor, in press], the role of context - historical, generational, political, geographic, ethnic, and familial - in acculturation research (and cultural studies generally) is in need of further empirical attention.

Acculturation is simultaneously intrapersonal, interpersonal, and contextually influenced, and understanding the various factors that shape this process will provide a much needed understanding of cultural identity and adaptation. For example, how does biculturalism develop over time, and how do cultural and contextual factors (e.g., parents, peers, schools, media) influence the ways in which it unfolds? How do the expectations and reactions of the receiving culture affect the ways in which immigrants acculturate, and the extent to which biculturalism is adaptive? The fact that these questions are ready to be posed suggests that the field of cultural studies is ready to take its next major step.

\section{Acknowledgements}

The preparation of this article was supported by grants DA019409 and DA026550 from the National Institute on Drug Abuse to Seth J. Schwartz, and by grant DA016310 from the National Institute on Drug Abuse to Jennifer B. Unger.

\section{References}

Barker, V., Giles, H., Noels, K., Duck, J., Hecht, M., \& Clément, R. (2001). The English-only movement: A communication analysis of changing perceptions of language vitality. Journal of Communication, 51, 3-37.

Benet-Martínez, V., \& Haritatos, J. (2005). Bicultural identity integration (BII): Components and psychosocial antecedents. Journal of Personality, 73, 1015-1050.

Benet-Martínez, V., Leu, J., Lee, F., \& Morris, M.W. (2002). Negotiating biculturalism: Cultural frame switching in biculturals with oppositional versus compatible cultural identities. Journal of CrossCultural Psychology, 33, 492-516.

Berry, J.W. (1997). Immigration, acculturation, and adaptation. Applied Psychology: An International Review, 46, 5-34.

Berry, J.W. (2006). Mutual attitudes among immigrants and ethnocultural groups in Canada. International Journal of Intercultural Relations, 30, 719-734.

Bruss, J. (2008). Experiences of discrimination reported by Turkish, Moroccan, and Bangladeshi Muslims in three European cities. Journal of Ethnic and Migration Studies, 34, 875-894.

Cabassa, L.J. (2003). Measuring acculturation: Where we are and where we need to go. Hispanic Journal of Behavioral Sciences, 25, 127-146.

Biculturalism and Context

Human Development 
CBS News (2004, March 3). France bans head scarves in school. http://www.cbsnews.com/stories/ 2004/02/02/world/main597565.shtml (accessed September 23, 2009).

Chen, S.X., Benet-Martínez, V., \& Bond, M.H. (2008). Bicultural identity, bilingualism, and psychological adjustment in multicultural societies: Immigration-based and globalization-based acculturation. Journal of Personality, 76, 803-838.

Cornelius, W. (2002). Ambivalent reception: Mass public responses to the 'new' Latino immigration to the United States. In M.M. Suárez-Orozco \& M.M. Páez (Eds.), Latinos: Remaking America (pp. 165-189). Berkeley: University of California Press.

Critelli, F. (2008). The impact of September 11th on immigrants in the United States. Journal of Immigrant and Refugee Studies, 6, 141-167.

Flannery, W.P., Reise, S.P., \& Yu, J. (2001). A comparison of acculturation models. Personality and Social Psychology Bulletin, 27, 1035-1045.

Gestsdóttir, S., \& Lerner, R.M. (2008). Positive development in adolescence: The development and role of intentional self-regulation. Human Development, 51, 202-224.

Huntington, S.P. (2004). Who are we? The challenges to America's national identity. New York: Simon \& Schuster.

Huynh, Q.L., Nguyen, A.M.T., \& Benet-Martínez, V. (in press). Bicultural identity integration. In S.J. Schwartz, K. Luyckx, \& V.L. Vignoles (Eds.), Handbook of identity theory and research. New York: Springer.

Lerner, R.M., Freund, A., DeStefanis, I., \& Habermas, T. (2001). Understanding developmental regulation in adolescence: The use of the Selection, Optimization, and Compensation model. Human Development, 44, 29-50.

Licata, L., \& Klein, O. (2002). Does European citizenship breed xenophobia? European identification as a predictor of intolerance towards immigrants. Journal of Community and Applied Social Psychology, 12, 323-337.

Licata, L., Sanchez-Mazas, M., \& Green, E.T. (in press). Identity and recognition in the relationship between host societies and immigrants in Europe: Towards an interactionist approach to prejudice. In S.J. Schwartz, K. Luyckx, \& V.L. Vignoles (Eds.), Handbook of identity theory and research. New York: Springer.

Park, Y.S., \& Kim, B.S.K. (2008). Asian and European American cultural values and communication styles among Asian American and European American college students. Cultural Diversity and Ethnic Minority Psychology, 14, 47-56.

Phinney, J.S., \& Devich-Navarro, M. (1997). Variations in bicultural identification among African American and Mexican American adolescents. Journal of Research on Adolescence, 7, 3-32.

Portes, A., \& Rumbaut, R.G. (2001). Legacies: The story of the immigrant second generation. Berkeley: University of California Press.

Portes, A., \& Rumbaut, R.G. (2006). Immigrant America: A portrait (3rd ed.). Berkeley: University of California Press.

Schwartz, S.J., Unger, J.B., Zamboanga, B.L., \& Szapocznik, J. (submitted). Rethinking the concept of acculturation: Implications for theory, measurement, and health research.

-Schwartz, S.J., \& Zamboanga, B.L. (2008). Testing Berry's model of acculturation: A confirmatory latent class approach. Cultural Diversity and Ethnic Minority Psychology, 14, 275-285.

Sterba, C.M. (2003). Good Americans: Italian and Jewish immigrants during the First World War. New York: Oxford University Press.

Szapocznik, J., Kurtines, W.M., \& Fernandez, T. (1980). Bicultural involvement and adjustment in Hispanic American youths. International Journal of Intercultural Relations, 4, 353- 365.

Tadmor, C.T., Tetlock, P.E., \& Peng, K. (2009). Acculturation strategies and integrative complexity: The cognitive implications of biculturalism. Journal of Cross-Cultural Psychology, 40, 105-139.

Umaña-Taylor, A.J. (in press). Ethnic identity and psychosocial functioning among ethnic minorities in the United States: Theory, research, and future directions. In S.J. Schwartz, K. Luyckx, \& V.L. Vignoles (Eds.), Handbook of identity theory and research. New York: Springer.

Umaña-Taylor, A.J., Bhanot, R., \& Shin, N. (2006). Ethnic identity formation during adolescence: The critical role of families. Journal of Family Issues, 27, 390-414.

Umaña-Taylor, A.J., Yazedjian, A., \& Bámaca-Gómez, M.Y. (2004). Developing the Ethnic Identity Scale using Eriksonian and social identity perspectives. Identity, 4, 9-38. 